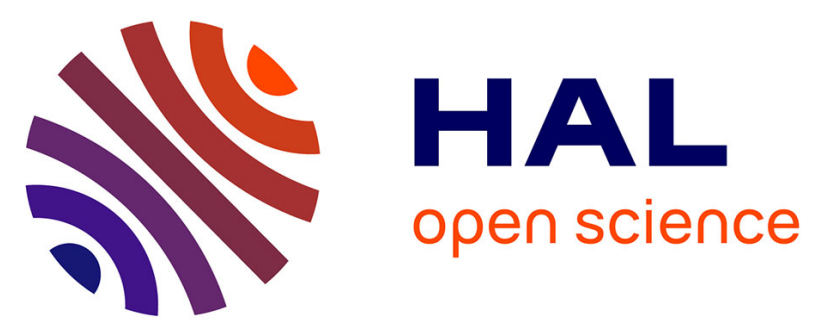

\title{
Thermal heating during microwave processing for cerium oxide particles packing: multiphysics modelling approach. Study of the effect of particle and neck sizes
}

Hussein Hammoud, François Valdivieso, Sébastien Vaucher

\section{- To cite this version:}

Hussein Hammoud, François Valdivieso, Sébastien Vaucher. Thermal heating during microwave processing for cerium oxide particles packing: multiphysics modelling approach. Study of the effect of particle and neck sizes. International Conference on Numerical Electromagnetic Modeling and Optimization for RF, Microwave, and Terahertz Applications (NEMO), Aug 2015, Ottawa, Canada. 10.1109/NEMO.2015.7415042 . emse-01526904

\section{HAL Id: emse-01526904 \\ https://hal-emse.ccsd.cnrs.fr/emse-01526904}

Submitted on 27 Aug 2021

HAL is a multi-disciplinary open access archive for the deposit and dissemination of scientific research documents, whether they are published or not. The documents may come from teaching and research institutions in France or abroad, or from public or private research centers.
L'archive ouverte pluridisciplinaire HAL, est destinée au dépôt et à la diffusion de documents scientifiques de niveau recherche, publiés ou non, émanant des établissements d'enseignement et de recherche français ou étrangers, des laboratoires publics ou privés.

\section{(c)(1)}

Distributed under a Creative Commons Attribution| 4.0 International License 
Thermal heating during microwave processing for cerium oxide particles packing: multiphysics modelling approach. Study of the effect of particle and neck sizes

\author{
Hussein Hammoud ${ }^{\mathrm{a}, \mathrm{b}}$, François Valdivieso ${ }^{\mathrm{a}}$, Sébastien Vaucher ${ }^{\mathrm{b}}$ \\ áLaboratoire Georges Friedel CNRS UMR 5307, St-Etienne, France \\ ${ }^{\mathrm{b}} \mathrm{S} w i s s$ Federal Laboratories for Materials Science and Technology (EMPA), Thun, Switzerland
}

Abstract: In this work a single mode resonant microwave cavity $(2.45 \mathrm{GHz})$ is loaded with spherical particles. A weakly coupled Electromagnetic-Thermal (EM-thermal) solver is used iteratively to determine how the microscopic geometry (local curvatures between the particles, grain size and neck size) modifies the electromagnetic field, and in turn the thermal field in the particles. The modelling is performed with the conformal Finite Element (FE) solver COMSOL Multiphysics. The dielectric and the thermal properties of cerium oxide (ceria) particles up to $1000^{\circ} \mathrm{C}$ have been determined in our previous study [1].

The main variables in this study are:

1 - The radius of the spherical ceria particle $[R, 3 * R, 5 * R]$.

2- The size of the neck between two particles $[\mathrm{X} / \mathrm{R}=0.1,0.15,0.2]$.

Keywords: EM-Thermal simulation, Cerium oxide, Microwave Processing, Effect of Neck Size.

\title{
Introduction
}

The microwave technology is one of the best candidates to improve the sintering of materials produced by powder technology. Its enables a rapid, selective and volumetric heating of the green bodies, that can be beneficial to the mechanical and physical properties of the final sintered parts $[2,3]$. Despite numerous efforts it remains unclear today how the local electromagnetic and thermal field gradients can influences the mass transfer mechanisms involved during sintering such as grain boundary diffusion and surface diffusion.

Moreover the microwave technology has used in the mechanism of the selective and rapid heating of many materials. It is also known that ceramic sintering is one of the biggest area of microwave applications [4].

Ceria or cerium dioxide $\left(\mathrm{CeO}_{2}\right)$ ceramic material has important uses, such as UV filters, electrolytes in SOFC (solid oxide fuel cell) technology and as non-radioactive uranium dioxide simulant, can be extensively studied for the nuclear waste recycling technology $[5,6]$.

Today, the advancements in numerical techniques and development of practical software stimulate the interest in modeling of the microwave and RF processes, especially for the systems which have multiphysics problems (thermal, mechanical and electromagnetic aspects) [7]. Hence, we present here the results of EM and thermal microwave heating in single mode applicator at $2.45 \mathrm{GHz}$ using the FE solver COMSOL Multiphysics This study will give the information needed for our experimental study and will be compared to it in our next work.

\section{Model and material parameters}

We present a model a single mode standard cavity of $86 \times 43 \mathrm{~mm}$ which was developed recently in our laboratory (Mines Saint-Etienne). The waveguide has a length of $260 \mathrm{~mm}$ and electromagnetic waves in rectangular TE10 mode at $2.45 \mathrm{GHz}$. The microwave input power was 
fixed at $1 \mathrm{KW}$ and the spherical ceria sample was placed in an intense electric field position in an alumina crucible which is known as the best way to guarantee an efficient microwave heating. The crucible properties were imposed as in case of microwave-transparent materials in order to avoid the perturbation of the electromagnetic behavior of the sample. A rectangular iris has an opening of $65 \mathrm{~mm}$ and is located between the port excitation of the waves and the sample position. The presence of the iris was necessary in order to reflect the backward waves to get the resonance which means that the electromagnetic energy increases because of the multi-reflected radiation in the cavity. This phenomenon of resonance introduces stationary medium of microwaves radiation. Moreover, the size and the position of the iris were optimized in experimental and simulation studies which are not included in this paper.

The simulation process can be described as an iterative process where the multiphysics problem follows the different steps mentioned in below:

First, an electromagnetic stationary calculation was made everywhere in the cavity and within the sample taking into account the dielectric properties of the sample and the boundary conditions of the cavity walls to provide the energy absorbed. Then, the energy absorbed by the sample was served as a local heat source. The different losses coming from the radiation of the sample surface and the heat flow assumed for the air were also included in the calculation in a time domain whereas the electromagnetic study was in frequency domain. The cavity walls were perfectly conducting.

The different thermal and dielectric parameters up to $1000^{\circ} \mathrm{C}$ of the ceria sample were calculated in previous study [1].

The relative permittivity) and the thermal parameters of the sample as function of temperature are given in the table 1 below:

\begin{tabular}{|c|c|}
\hline Relative permittivity & Specific heat capacity \\
$7.9519+0.0087 * T-j^{*}\left(1.4354 E^{-14} * T^{5}-4.4388 E^{-11} * T^{4}\right.$ & $5.421 E^{-7} * T^{3}-1.4389 E^{-3} T^{2}$ \\
$\left.+5.2856 E^{-8} * T^{3}-2.9991 E^{-5} * T^{2}+8.0780 E^{-3} * T-0.8058\right)$ & $+1.2612 * T+62.208$ \\
& $(\mathrm{~J} / \mathrm{Kg} . \mathrm{K})$ \\
\hline Emissivity & Thermal conductivity \\
$3.4080 E^{-7} * T^{2}-1.2404 E^{-3} * T+1.432$ & $-1.157 * \log (T)+8.7001(\mathrm{~W} / \mathrm{m} . \mathrm{K})$ \\
\hline
\end{tabular}

Table 1: Thermal and dielectric parameters of ceria

\section{Results}

We present in this section the results obtained for different radius of the spherical sample as well as for different neck size between two samples.

Firstly, the figures 1a), b), c) show the variation of electric field for 3 different radii of the spherical sample (1,3 and $5 \mathrm{~mm}$ ). Then, in the figures $1 \mathrm{~d})$, e), f) we present the distribution of the temperature for it. From the figure 1, we can easily see that when the size of the particle increases the temperature increases rapidly from $438{ }^{\circ} \mathrm{C}$ to $1127^{\circ} \mathrm{C}$ and the electric field is slightly dependant on the size as well (see figures 1a) to 1c)).

Secondly, the figures $2 \mathrm{a}), \mathrm{b})$ and c) for 3 different neck size $(\mathrm{X} / \mathrm{R}=0.1,0.15,0.2)$ between 2 particles when their radius was fixed at $5 \mathrm{~mm}$. The figure 2 shows that the effect of the neck size is negligible on the heating behaviour whereas the maximum temperature is lower compared to one sphere $\left(761\right.$ to $764{ }^{\circ} \mathrm{C}$ ). This difference can be explained by the different position of the sample; in case of 2 spheres the neck was placed in an intense position of the electric field when 
in the previous case the center of the sample was placed in this position. A temperature gradient was observed between the core and the surface of the sample as well as its core and its neck.

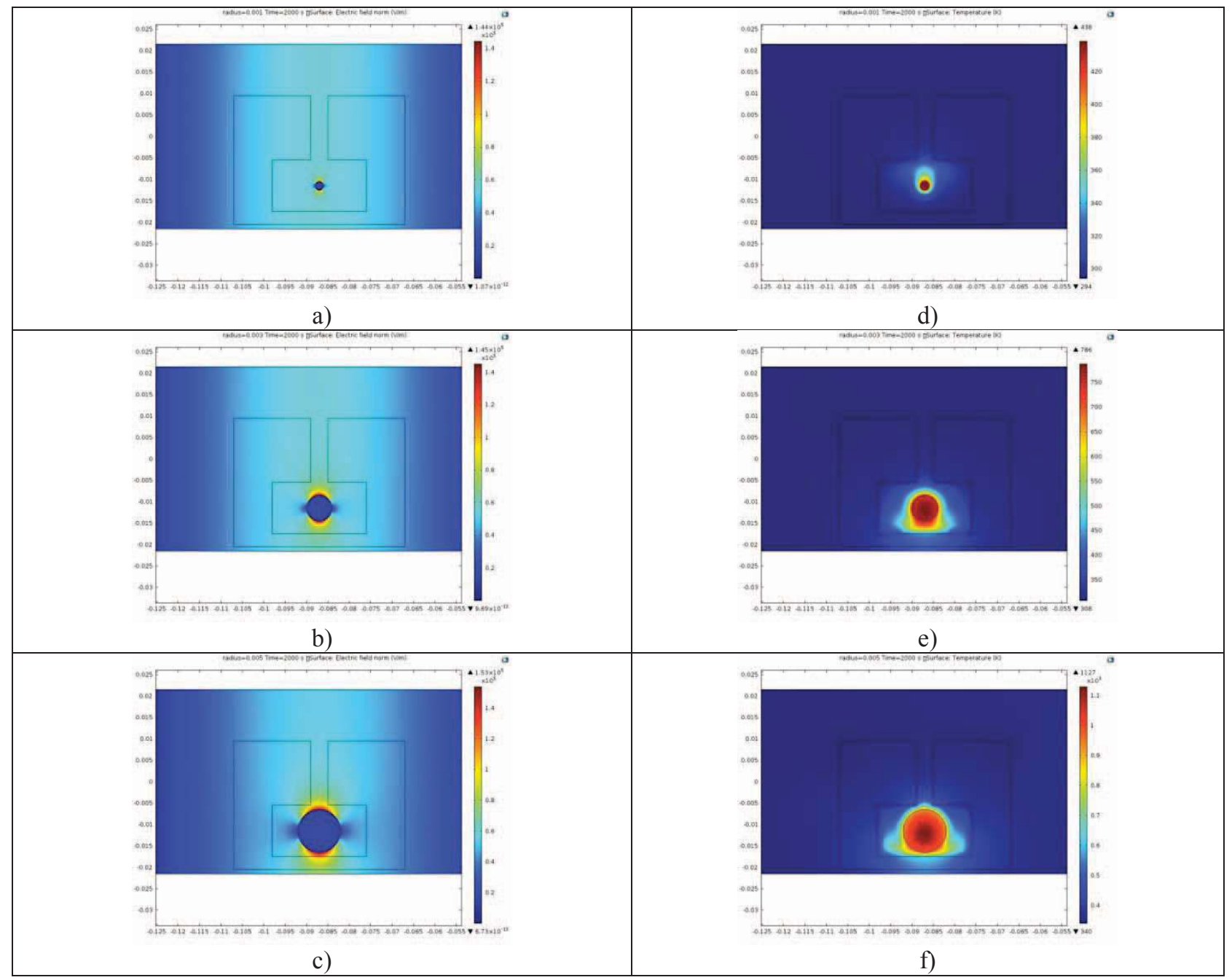

Fig. 1. Variation of the electric field norm for different radii a) 1, b) 3 and c) $5 \mathrm{~mm}$ and temperature distributions of ceria sphere for different radii: d) 1, e) 3 and f) $5 \mathrm{~mm}$.

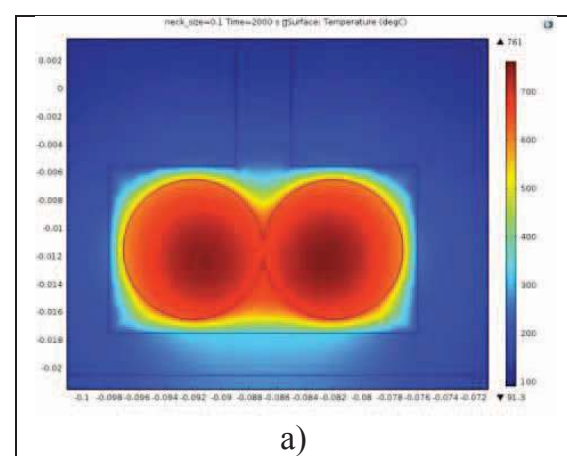

a)

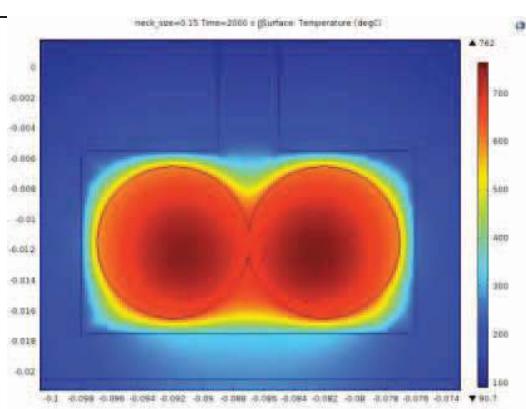

b)

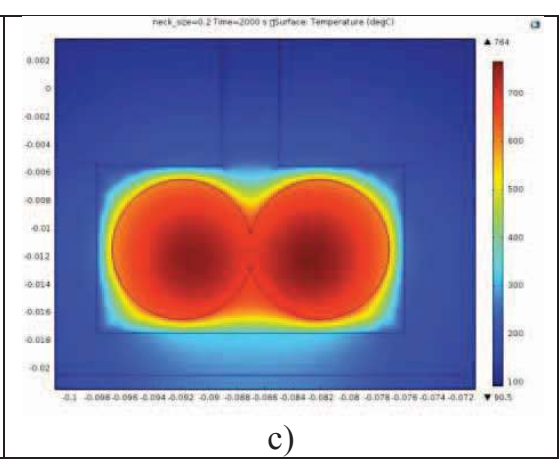

c)

Fig. 2. Temperature distributions of ceria spheres for different neck size: a) 0.1, b) 0.15 and c) 0.2. 


\section{Conclusion}

The results show that the size of 1 particle has a strong effect on the electric field and therefore on the microwave heating behaviour (the temperature varies from 438 to $1127^{\circ} \mathrm{C}$ ) whereas the effect of neck size on the heating is negligible. Moreover, the existence of large temperature gradients (about 150 to $200{ }^{\circ} \mathrm{C}$ ) can be a driving force for sintering.

\section{References}

[1] H.Hammoud, S. Vaucher and F. Valdivieso, Effect of the porosity on the thermophysical properties of cerium oxide up to $1300 \mathrm{~K}$ and their implications for microwave sintering of spherical ceria gels, AMPERE 2013 the 14th International Conference on Microwave and High Frequency Heating, Nottingham,UK.

[2] P. Yadoji, R. Peelamedu, D. Agrawal, R. Roy, Microwave sintering of Ni-Zn ferrites: comparaison with conventional sintering, Materials Science and Engineering B 98 269-278 (2003).

[3] D. Agrawal, Microwave sintering of ceramics, composites, metals, and transparent materials, Journal of Materials Education 19 49-58 (1999).

[4] W. H. Sutton, Microwave processing of ceramic materials, Am. Ceram. Soc,68 [2] 376-86 (1989).

[5] M. Jalilpour and M. Fathalilou, Effect of aging time and calcination temperature on the cerium oxide nanoparticles synthesis via reverse co-precipitation method, International J. of the Physical Sciences, Vol.7(6), 944948 (2012).

[6] Fundamentals of the behavior of fission products in oxide nuclear fuels, University of Oxford.

[7] D. Bouvard et al., Multiphysics Simulation of Microwave Sintering in a Monomode Cavity, 12th Seminar Computer Modeling in Microwave Engineering \& Applications, Grenoble, France, 2010. 